\title{
PENGARUH TEKNIK RELAKSASI BENSON TERHADAP PENURUNAN SKALA NYERI POST APPENDIXTOMY DI RSUD PORSEA
}

\author{
Melva Manurung ${ }^{1}$, Tumpal Manurung ${ }^{2}$, Perawaty Siagian ${ }^{3}$ \\ Akper Yayasan Tenaga Pembangunan Arjuna Laguboti \\ Jalan YP Arjuna Pintubosi Laguboti \\ Email: melva_manroe84@yahoo.com
}

\begin{abstract}
Pain is a sensation that is complex, unique, universal and individual. Nursing interventions that can be done in reducing pain in patients with post operative appendectomy can be done by teaching Benson relaxation technique. The purpose of this study was to analyze the Effect of Benson Relaxation Technique on the decrease of Post Appendixtomy pain scale at Porsea Hospital Year 2019. The research design used was quasi experimental research with a static group comparison design (posttest only control group design). The population is of Appendixtomy patients in Porsea Hospital with a sample of 18 respondents. The gauge uses a research guide for Benson Relaxation on the post-Appendixtomy pain scale reduction at Porsea Hospital. Data were analyzed by t test. The results of the pre-experimental t-test analysis of the control group and the preexperimental intervention group obtained a value of $p=0.003$, there was a difference in the decrease in post Appendixomy pain scale after Benson relaxation. The result of t-test post experiment of control group and post experiment of intervention group obtained $p$ value $=0.000$, there is difference of difference of decrease of pain scale post Appendixtomy after Benson relaxation. The role of special nurses as care givers in reducing the scale of pain, is more sensitive to patients with various diseases that cause pain. Nurses in the role of nursing careers especially in decreasing the scale of pain, more sensitive to special populations ie individuals with various diseases that cause pain
\end{abstract}

Keywords: Benson relaxation, pain scale, appendixtomy

\section{PENDAHULUAN}

Apendiksitis adalah peradangan pada apendiks vermikularis (sisa apex sekum yang tidak memiliki fungsi) yang mengenai samua dinding organ (Sjamsuhidajat, 2012). Apendiksitis dapat terjadi pada semua golongan usia, paling sering terjadi antara usia 10-30 tahun, dengan presentasi pria lebih sering daripada wanita, dan remaja lebih sering daripada orang tua. Keluhan apendiksitis biasanya berawal dari nyeri atau rasa tidak enak di sekitar umbilikus, umumnya berlangsung lebih dari 1 atau
2 hari, dan nyeri akan bergeser dalam 212 jam kekuadran kanan bawah, menetap dan diperberat bila berjalan (Berman \& Kozier, 2012).

Manifestasi klinis dari apendiksitis ditemukan keluhan anoreksia, mual, muntah, demam dan peningkatan leukosit. Pada pemeriksaan fisik ditemukan nyeri tekan lokal pada titik McBurney, nyeri tekan lepas (rebound tenderness), dan nyeri alih (referred pain). Pada apendiksitis yang sudah mengalami perforasi muncul gejala berupa nyeri, nyeri tekan dan spasme, 
disertai hilangnya rasa nyeri secara dramatis untuk sementara (Grace \& Neil, 2011).

\section{Hasil Survey Kesehatan Rumah} Tangga (SKRT) di Indonesia, insiden apendisitis di Indonesia menempati urutan tertinggi di antara kasus kegawatan abdomen lainya. Jarang terjadi pada usia di bawah 2 tahun, banyak pada dekade kedua dan ketiga, tetapi dapat terjadi pada semua usia (Grace \& Neil, 2011).

Penatalaksanaan apendisitis adalah dengan tindakan pembedahan (apendiktomi). Apendiktomi dapat dilakukan dengan menggunakan dua metode pembedahan, yaitu secara tehnik terbuka/pembedahan konvensional (laparatomi) atau dengan tehnik laparaskopi yang merupakan tehnik pembedahan minimal infasif dengan metode terbaru yang sangat efektif (Berman \& Kozier, 2012).

Insidens tertinggi pada kelompok umur 20-30 tahun, setelah itu menurun. Sedangkan insidens pada laki-laki dan perempuan umumnya sebanding, kecuali pada umur 20-30 tahun, insidens pada laki-laki lebih tinggi (Sjamsuhidajat, 2012). Apendiktomi harus segera dilaksanakan jika ditemukan apendisitis pada seseorang (Mitchell, 2013). Komplikasi setelah operasi apendiktomi antara lain perdarahan, perlengketan organ dalam, dan infeksi pada daerah operasi.

Masa pemulihan pasien post operasi membutuhkan waktu yang bervariasi. Dalam penelitian Mulyono (2010), pemulihan pasien post operasi membutuhkan waktu rata-rata 72,45 menit. Pada umumnya pasien akan merasakan nyeri yang hebat pada 2 jam pertama pasca operasi dikarenakan pengaruh obat anastesi mulai hilang (Berman \& Kozier, 2012).

Nyeri merupakan sensasi yang rumit, unik, universal dan bersifat individual, sehingga tidak ada dua individu yang mengalami nyeri yang sama dan tidak ada dua kejadian nyeri yang sama menghasilkan respon atau perasaan yang identik pada individu. Hal tersebut yang menjadi dasar bagi perawat untuk memberikan intervensi keperawatan dalam mengatasi nyeri (Asmadi, 2013).

Intervensi atau tindakan mandiri keperawatan yang dapat dilakukan dalam mengurangi nyeri pada pasien dengan post operasi apendiktomi salah satunya yaitu dengan mengajarkan tehnik relakasasi Benson (Berman \& Kozier, 2012). Nyeri dapat diatasi dengan penatalaksanaan nyeri yang bertujuan untuk meringankan atau mengurangi rasa nyeri sampai tingkat kenyamanan yang dirasakan oleh klien.

Dalam Anas, Tamsuri (2007), Ada dua cara penatalaksanaa nyeri beberapa 
teknik non farmakologis yang dapat diterapkan dalam mengatasi nyeri yaitu teknik pernafasan, aromaterapi, audionalgesia, akupuntur, transcutaneus electric nerve stimulations (TENS), kompres dengan suhu dingin panas, sentuhan pijatan dan hipnotis (Gondo \& Sugiharta, 2012). Salah satu upaya non farmakologis untuk mengatasi nyeri adalah teknik relaksasi. Teknik relaksasi terbagi atas 4 macam yaitu relaksasi otot (progressive muscle relaxation), pernafasan (diaphragmatic breathing), meditasi (attentionfocusing exercise) dan relaksasi prilaku (behavioral relaxation) (Miltenbarger, 2012). Kelebihan latihan teknik relaksasi dibandingkan dengan teknik lain adalah teknik relaksasi lebih mudah dilakukan bahkan dalam kondisi apapun serta tidak memiliki efek samping apapun (Novitasari \& Aryana, 2013).

Relaksasi benson merupakan pengembangan metode respon relaksasi pernafasan dengan melibatkan faktor keyakinan pasien yang dapat menciptakan suatu lingkungan internal sehingga dapat membantu pasien mencapai kondisi kesehatan dan kesejahteraan lebih tinggi (Benson \& Prector, 2000). Cara kerja teknik relaksasi benson ini adalah berfokus pada kata atau kalimat tertentu yang diucapkan berulang kali dengan ritme teratur. Pernafasan yang panjang dapat meberikan energy yang cukup, karena pada waktu menghembuskan nafas mengeluarkan karbondioksida (CO2) dan saat menghirup nafas panjang mendapatkan oksigen yang sangat diperlukan tubuh untuk membersihkan darah dan mencegah kerusakan jaringan otak akibat kekurangan oksigen (hipoksia). Saat tarik nafas panjang otototot dinding perut (rektus abdominalis, transversus abdominalis, internal dan ekternal obligue) menekan iga bagian bawah kearah belakang sera mendorong sekat diafragma ke atas dapat berakibat meninggikan tekanan intra abdominal, sehingga dapat merangsang aliran darah baik vena cava inferior maupun aorta abdominalis, mengakibatkan aliran darah (vaskularisasi) menjadi meningkat keseluruh tubuh terutama organ-organ vital seperti otak, sehingga $\mathrm{O}_{2}$ tercukupi didalam otak dan tubuh menjadi rileks (Benson \& Proctor, 2000).

Penelitian Novitasari dan Aryana (2013) menunjukkan ada pengaruh signifikan teknik relaksasi benson terhadap tingkat stress pada lansia tersebut dengan $\mathrm{p}$ value 0,002 . Selain itu, penelitian yang dilakukan oleh Trisnayati (2010) bahwa teknik relaksasi benson berpengaruh terhadap pemenuhan kebutuhan tidur pada lansia. Demikian juga penelitian oleh Zees (2012) dan Suhartini Nurdin, dkk (2013) menyatakan bahwa pemberian tehnik 
relaksasi menurunkan intensitas nyeri pada pasien post operasi. Beberapa tehnik relaksasi yang sudah ada antara lain relaksasi otot, relaksasi kesadaran indera, relaksasi meditasi, yoga dan relaksasi hipnosa (Utami, 2013).

Hasil studi pendahuluan peneliti di RSUD Porsea, pada Februari 2019, peneliti menemukan tiga orang pasien yang melakukan appendixtomy mengeluh nyeri. Dua orang mengatakan nyeri berat sedangkan satu ibu mengatakan nyeri sedang. Untuk mengurangi rasa nyeri, klien biasanya mengubah posisi tubuh dan menyentuh daerah yang sakit. Rasa nyeri ini mengakibatkan klien malas bergerak, selain itu klien hanya diberi terapi analgetik untuk mengurangi rasa nyeri.

Terapi analgetik ini hanya diberikan di hari pertama setelah post operasi, setelah itu klien tidak diberikan terapi analgetik lagi kecuali klien merasakan nyeri yang tidak tertahankan, maka relaksasi benson ini dapat membantu klien untuk mengurangi rasa nyeri yang klien rasakan tanpa memiliki efek samping apapun. Angka appendixtomi di RSU D Porsea tahun 2016 mencapai 26 orang, pada tahun 2017 yaitu 31 sedangkan pada bulan Januari sampai Februari 2018 yaitu 45 orang (Rekam Medik RSU D Porsea, 2018).

\section{METODE}

Desain penelitian ini menggunakan rancangan penelitian kuasi eksperimen dengan rancangan perbandingan kelompok statis (posttest only control group design). Penelitian ini akan melihat pengaruh teknik relaksasi Benson terhadap penurunan skala nyeri post Appendixtomy di RSUD Porsea. Kelompok eksperimen menerima perlakuan sesuai dengan SOP, sedangkan kelompok pembanding diberikan perlakuan sesuai dengan kebiasaan ruangan. Sampel yang diteliti sebanyak 18 orang.

\section{HASIL DAN PEMBAHASAN}

Hasil

Karakteristik responden Tabel 1.

Distribusi Frekuensi Responden Kelompok Kontrol Berdasarkan Data Demografi di RSUD Porsea $(n=9)$.

\begin{tabular}{clll}
\hline No. & Karakteristik & $(\boldsymbol{f})$ & $(\%)$ \\
\hline 1 & Responden & & \\
\hline Usia & & \\
& $<17$ tahun & 3 & 33.3 \\
& 18-25 tahun & 3 & 33.3 \\
& 26-35 tahun & 2 & 22.2 \\
& 36-45 tahun & 1 & 11.1 \\
& Jenis Kelamin & & \\
& Wanita & 3 & 33.3 \\
& Pria & 6 & 66.7 \\
3 & Pendidikan & & \\
& SMP & 1 & 11.1 \\
& SMA & 2 & 22.2 \\
& PT & 5 & 55.6 \\
& Tidak sekolah & 1 & 11.1 \\
4 & Pekerjaan & & \\
& Siswa & 3 & 33.3 \\
& Mahasiswa & 3 & 33.3 \\
& Pegawai & 2 & 22.2 \\
& Tidak bekerja & 1 & 11.1 \\
\hline
\end{tabular}


Hasil penelitian didapatkan bahwa rata-rata usia responden kelompok intervensi mayoritas sebanyak 5 orang (55.6\%) berada pada usia 18-35 tahun, mayoritas berjenis kelamin pria (66.67\%), dengan pendidikan adalah mahasiswa atau perguruan tinggi sebanyak 6 orang $(66.7 \%)$, dan pekerjaan mayoritas mahasiswa.

Tabel 2.

Distribusi Frekuensi Responden Kelompok Intervensi Berdasarkan Data Demografi di RSUD Porsea $(\mathbf{n}=9)$

\begin{tabular}{clcc}
\hline No. & Karakteristik & $(\boldsymbol{f})$ & $(\boldsymbol{\%})$ \\
& Responden
\end{tabular}

Hasil penelitian pada kelompok kontrol pre eksperimen yang mengalami nyeri nilai 7 terdapat 6 responden (66.7\%), mengalami nilai nyeri 8 sebanyak 2 orang (22.2\%) dan 1 responden $(11.1 \%)$ memiliki nilai nyeri 6. Pada kelompok kontrol post eksperimen yang mengalami nyeri nilai
7 terdapat 7 responden $(77.8 \%), 2$ responden $(22.2 \%)$ memiliki nilai nyeri 6. Hasil penelitian pada kelompok intervensi pre eksperimen mengalami nyeri nilai 7 terdapat 6 responden (66.7\%), mengalami nilai nyeri 8 sebanyak 2 orang (22.2\%) dan 1 responden $(11.1 \%)$ memiliki nilai nyeri 6. Pada kelompok intervensi post eksperimen mengalami nyeri nilai 5 terdapat 7 responden $(77.8 \%)$, mengalami nilai nyeri 6 sebanyak 2 orang $(22.2 \%)$.

Pengaruh Teknik Relaksasi Benson terhadap penurunan skala nyeri post Appendixtomy Kelompok Kontrol dan kelompok Intervensi di RSUD Porsea

Untuk menguji pengaruh Teknik Relaksasi Benson terhadap penurunan skala nyeri post Appendixtomy di RSUD Porsea maka dilakukan analisa bivariat pada kelompok kontrol dan kelompok intervensi. Tingkat kemaknaan ditetapkan sebesar 95\%, artinya bila nilai $p<0,05$ maka dapat disimpulkan ada pengaruh Teknik Relaksasi Benson terhadap penurunan skala nyeri post Appendixtomy di RSUD Porsea, bila nilai $p>0,05$ disimpulkan tidak ada pengaruh Teknik Relaksasi Benson terhadap penurunan skala nyeri post Appendixtomy di RSUD Porsea.

Hasil analisa Uji t pre eksperimen dan post eksperimen kelompok kontrol diperoleh nilai $p=0,00$, yang berarti 
nilai $p<0.05$ maka dapat disimpulkan ada perbedaan skala nyeri post Appendixtomy di RSU D Porsea setelah dilakukan Teknik Relaksasi Benson.

Tabel 3.

Pengaruh Relaksasi Benson terhadap Penurunan Nyeri Pre Eksperimen Pada Kelompok Kontrol Dan Kelompok Intervensi di RSUD Porsea

\begin{tabular}{cc}
\hline & $\begin{array}{c}\text { Pre eksperimen } \\
\text { Kelompok kontrol } \\
\text { - intervensi }\end{array}$ \\
\hline $\mathrm{Z}$ & $-6.051(\mathrm{a})$
\end{tabular}

Asymp. Sig. (20,00 tailed)

Hasil analisa uji $t$ pre eksperimen kelompok kontrol dan pre eksperimen kelompok intervensi diperoleh nilai $p=0.003$, yang berarti nilai $p<0.05$ maka dapat disimpulkan ada perbedaan penurunan skala nyeri post Appendixtomy antara pre eksperimen kelompok kontrol dengan pre eksperimen kelompok intervensi kontrol di RSUD Porsea setelah dilakukan relaksasi Benson.

Tabel 4.

Pengaruh Teknik Relaksasi Benson terhadap penurunan skala nyeri post Appendixtomy pada kelompok kontrol dan Intervensi di RSUD Porsea

\begin{tabular}{|c|c|}
\hline & $\begin{array}{c}\text { Kelompok } \\
\text { kontrol-intervensi }\end{array}$ \\
\hline t-independent & 216.000 \\
\hline $\mathbf{Z}$ & -2.948 \\
\hline $\begin{array}{l}\text { Asymp. Sig. (2- } \\
\text { tailed) }\end{array}$ & .003 \\
\hline
\end{tabular}

Hasil analisa uji $t$ post eksperimen kelompok kontrol dan post eksperimen kelompok intervensi diperoleh nilai $p=0,00$, yang berarti nilai $p<0.05$ maka dapat disimpulkan ada perbedaan perbedaan penurunan skala nyeri post Appendixtomy antara pre eksperimen kelompok kontrol dengan pre eksperimen kelompok intervensi kontrol di RSU D Porsea setelah dilakukan relaksasi Benson.

\section{Pembahasan}

Hasil analisa uji $t$ pre eksperimen dan post eksperimen kelompok kontrol diperoleh nilai $p=0,00$, yang berarti ada perbedaan penurunan skala nyeri pada kelompok kontrol yang dilakukan relaksasi Benson. Hasil analisa uji $t$ pre eksperimen dan post eksperimen kelompok intervensi diperoleh nilai $p=0,00$, yang berarti ada perbedaan penurunan skala nyeri pada kelompok intervensi yang dilakukan fisioterapi dada.

Hasil analisa uji $t$ pre eksperimen kelompok kontrol dan pre eksperimen kelompok intervensi diperoleh nilai $p=$ 0,003 , yang berarti ada perbedaan penurunan skala nyeri antara pre eksperimen kelompok kontrol dengan pre eksperimen kelompok intervensi yang dilakukan relaksasi Benson. Hasil 
analisa uji $t$ post eksperimen kelompok kontrol dan post eksperimen kelompok intervensi diperoleh nilai $p=0,00$, yang berarti perbedaan penurunan skala nyeri antara post eksperimen kelompok kontrol dengan post eksperimen kelompok intervensi yang dilakukan relaksasi Benson.

Nyeri merupakan fenomena yang multidimensional. Ahles et al. (2010) mengkategorikan lima dimensi dari nyeri yang dialami. Identifikasi dimensi nyeri ini mulanya diperuntukan untuk nyeri-nyeri pada kasus-kasus kanker. Kelima dimensi ini meliputi: dimensi fisiologi, sensori, afektif, cognitive, dan behavior (perilaku). Intensitas nyeri, intensitas nyeri adalah sejumlah nyeri yang dirasakan oleh individu dan sering kali digambarkan dengan kata-kata seperti ringan, sedang dan berat. Intensitas nyeri juga dapat dilaporkan dengan angka yang menggambarkan skor dari nyeri yang dirasakan sedangkan kualitas nyeri adalah berkaitan dengan bagaimana nyeri itu sebenarnya dirasakan individu. Kualitas nyeri digambarkan dengan berdenyut, menyebar, menusuk, terbakar dan gatal. Pada kasus nyeri kanker, pasien sering melaporkan kualitas nyerinya seperti nyeri tajam, berdenyut, pedih, menusuk, tertekan berat, atau juga bertambah (McGuire \& Sheidler, 2013).
Relaksasi benson merupakan salah satu cara untuk mengurangi nyeri dengan melibatkan faktor keyakinan pasien yang dapat menciptakan suatu lingkungan internal sehingga dapat membantu pasien mencapai kondisi kesehatan dan kesejahteraan lebih tinggi (Benson \& Proctor, 2000).

Hasil penelitian ini sejalan dengan Novitasari dan Aryana (2013) menunjukkan ada pengaruh signifikan teknik relaksasi Benson terhadap tingkat nyeri pada lansia tersebut dengan $\mathrm{p}$ value 0,002 . Selain itu, penelitian yang dilakukan oleh Trisnayati (2010) bahwa teknik relaksasi benson berpengaruh terhadap pemenuhan kebutuhan tidur pada lansia.

Penelitian terkait lainnya yang mendukung adalah penelitian yang dilakukan oleh Datak (2012) yang berjudul penurunan nyeri pasca bedah pasien tur prostat melalui relaksasi benson menunjukkan bahwa adanya pengurangan rasa nyeri pada pasien yang diberikan intervensi relaksasi benson sehingga pada penelitian ini merekomendasikan relaksasi benson sebagai bahan pertimbangan. Demikian juga penelitian oleh Zees (2012) dan Suhartini Nurdin, dkk (2013) menyatakan bahwa pemberian tehnik relaksasi menurunkan intensitas nyeri pada pasien post operasi. Beberapa tehnik relaksasi yang sudah ada antara 
lain relaksasi otot, relaksasi kesadaran indera, relaksasi meditasi, yoga dan relaksasi hipnosa (Utami, 2013).

Dalam penelitian yang dilakukan oleh Rambod M.,et al, (2013) menyebutkan relaksasi benson mampu meningkatkan kualitas tidur pasien dan 23 mengurangi penggunaan obat tidur pada pasien yang menjalani hemodialisa. Hal ini senada dengan ungkapan Setyowati, H. \& Green (2004) yang menyebutkan salah satu manfaat terapi relaksasi benson adalah untuk mengatasi insomnia. Manfaat lain dari relaksasi benson adalah mengurangi skala nyeri.

Relaksasi Benson ini dapat digunakan untuk mengurangi skala nyeri pada orang yang mengalami nyeri karena kelainan parenkim paru seperti fibrosis dan pasien yang mendapat ventilasi mekanik (Afiyah, 2009).

Hasil penelitian Bernhart, (2010), yang dilakukan di Australia menunjukkan fisioterapi dada merupakan tindakan sederhana, mudah memberikan intervensi, menggunakan sedikit atau tidak ada peralatan. Fisioterapi dada terbukti efektif, dapat mengurangi penumpukan secret pada pasien.

Perawat dalam peran sebagai pemberi asuhan keperawatan khususnya dalam penurunan skala nyeri, lebih peka terhadap populasi khusus yaitu individu dengan berbagai penyakit yang menyebabkan nyeri. Berdasarkan hasil obeservasi peneliti pada saat penelitian keluarga memiliki peran yang sangat penting mendampingi pasien dalam proses relaksasi Benson, karena hal ini dapat menurunkan skala nyeri dengan memberikan ketenangan psikologis pada pasien tersebut.

\section{Kesimpulan}

Hasil penelitian pada kelompok kontrol pre eksperimen terdapat 6 responden $(66.7 \%)$ yang mengalami nyeri nilai 7,2 orang $(22.2 \%)$ mengalami nilai nyeri 8 dan 1 responden (11.1\%) memiliki nilai nyeri 6 . Hasil penelitian pada kelompok intervensi pre eksperimen terdapat 6 responden $(66.7 \%)$ mengalami nyeri nilai 7. Hasil analisa uji $\mathrm{t}$ pre eksperimen dan post eksperimen kelompok kontrol diperoleh nilai $p=0.000$, yang berarti nilai $p<0.05$ maka dapat disimpulkan ada perbedaan skala nyeri post Appendixtomy di RSUD Porsea setelah dilakukan Teknik Relaksasi Benson. Hasil analisa uji $t$ pre eksperimen dan post eksperimen kelompok intervensi diperoleh nilai $p=0.000$, yang berarti nilai $p<0.05$ maka dapat disimpulkan ada perbedaan perbedaan skala nyeri post Appendixtomy di RSUD Porsea setelah dilakukan Teknik Relaksasi Benson 


\section{DAFTAR PUSTAKA}

Ahles, T. A., Blanchard, E. B., \& Ruckdeschel, J. C. (1983). The multidimensional nature of cancer related pain, Pain, 17, 272-288.

Anas, Tamsuri (2007). Konsep dan Penatalaksanaan Nyeri. Jakarta: EGC.

Asmadi (2013). Teknik Prosedural Keperawatan Konsep dan Aplikasi Kebutuhan dasar Klien. Salemba medika. Jakarta.

Afiyah. (2009). Pengaruh tehnik relaksasi Benson terhadap Skala Nyeri pada Kelainan Parenkim Paru, Jurnal Kesehatan vol. 1 no. 3.

Benson, H., \& Prector, W. (2000). Dasar-dasar respon relaksasi. Bandung: Kaifa

Berman, S., \& Kozier. (2012). Buku ajar praktik keperawatan klinis kozier. Jakarata; EGC.

Datak, G. (2012). Efektifitas Relaksasi Benson Terhadap Nyeri Pasca Bedah pada Pasien Transurethral Resection of The Prostate di Rumah Sakit Umum Pusat Fatmawati. Jakarta (tesis). Jakarta: Universitas Indonesia. Tidak dipublikasikan

Gondo, K. H., \& Sugiharta. K. (2012). Profil Operasi Seksio Sesarea di SMF Obstetri \& Ginekologi RSUP Sanglah Denpasar, CDK 175/ vol.37 no. 2 .

Grace, Pierce A, \% Neil R. Borley. (2011). At a Glance Ilmu Bedah. Edisi ketiga. Jakarta: Erlangga.

McGuire, D. B and Sheildler, V. R. (2013). Pain. In S. L. Groen, M. H. Fragge, M. Goodman, and C. H. Yarbro (Edt.). Cancer nursing: Principles and practice (3rd Ed.)(pp. 499-556). Boston, NA: Jones and Bartlett Publisher.

Mitchell M, M.D. (2013), heart-and soul healing. Philadelphia: Lippincott.

Mulyono, M. H., Hamzah. (2010). Faktor yang berpengaruh terhadap penyembuhan post operasi
Appendiktomi di RS tingkat III Ambon. Jurnal e-KP, Vol. 1 No. 1.

Novitasari, D. \& Aryana, K. O. (2013). Pengaruh Tehnik Relaksasi Benson Terhadap Penurunan Tingkat Stres Lansia di Unit Rehabilitas Sosial Wening Wardoyo Ungaran. J. Keperawatan Jiwa, 1(2): 186-295.

Nurdin, Si. (2013), Pengaruh Tehnik Relaksasi Terhadap Intesitas Nyeri pada Pasien Post Operasi Fraktur Di Ruang Irnina A BLU RSUP Prf Dr. R.D Kandou Manado, ejournal keperawatan (e-Kp) Volume 1. Nomor 1

Rambod, M., Sharif, F., PouraliMohammadi, N., et all. (2013). Evaluation of the effect of Benson's Relaxation Technique on pain and quality of life of haemodialysis patients: A randomized controlled triall. International Journal of Nursing Studies.

Setyowati, H. \& Green, C. W. (2004). Terapi alternatif. Yogyakarta: Yayasan Spiritia.

Sjamsuhidajat. (2012). Buku Ajar Ilmu Bedah, Edisi II. Jakarta : EGC

Utami P, Puspaningtyas DE. (2013). The miracle of herbs. Jakarta: AgroMedia Pustaka

Zees, Rini Fahriani. (2012), Pengaruh Tehnik Relaksasi terhadap Respon Adaptasi Nyeri pada Pasien Apediktomi di Ruang G2 Lantai II Kelas III BLUD RSU Prof. DR. H Aloei Saboe Kota Gorotalo, Jurnal Health \& Sport, Volume 5, Nomor 3 